\title{
Update on Treatment Options for Advanced Bile Duct Tumours: Radioembolisation for Advanced Cholangiocarcinoma
}

\author{
Pavan Najran $^{1}$ - Angela Lamarca ${ }^{2}$ - Damian Mullan ${ }^{1}$ • Mairéad G. McNamara ${ }^{2,3}$. \\ Thomas Westwood $^{1} \cdot$ Richard A. Hubner $^{2} \cdot$ Jeremy Lawrence $^{1} \cdot$ Prakash Manoharan $^{1}$. \\ Jon Bell ${ }^{1} \cdot$ Juan W. Valle ${ }^{2,3}$
}

Published online: 28 June 2017

(C) The Author(s) 2017. This article is an open access publication

\begin{abstract}
Cholangiocarcinoma is a rare form of gastrointestinal cancer with a poor prognosis. Patients often present with biliary obstruction or non-specific abdominal pain, and a high proportion of patients have advanced disease at initial diagnosis. The goal of this review is to discuss treatment options for patients with advanced bile duct tumours focusing on radioembolisation (RE) and its impact on overall survival. RE provides a therapeutic option for patients with unresectable cholangiocarcinoma. However, although systemic chemotherapy has demonstrated a survival benefit in randomised controlled trials, there is limited supporting evidence for the use of RE in this setting. Studies are mostly limited to single-centre, small cohorts with variable outcome measures. Additionally, patients included in these studies received a variety of previous therapies including chemotherapy, surgery or alternative intra-arterial therapy; therefore, a true assessment of overall survival benefit is difficult.
\end{abstract}

Keywords Intrahepatic $\cdot$ Cholangiocarcinoma $\cdot$ Liver radioembolisation $(\mathrm{RE}) \cdot$ Advanced $\cdot$ Treatment .

Chemotherapy

This article is part of the Topical Collection on Gastrointestinal Cancers

Juan W. Valle

juan.valle@ christie.nhs.uk

1 Department of Radiology, The Christie NHS Foundation Trust, Manchester, UK

2 Department of Medical Oncology, The Christie NHS Foundation Trust, Wilmslow Road, Manchester M20 4BX, UK

3 Division of Molecular and Clinical Cancer Sciences; Institute of Cancer Sciences, Faculty of Biology, Medicine and Health, University of Manchester, Manchester Academic Health Science Centre (MAHSC), Manchester M13 9PL, UK

\section{Introduction}

Biliary tract cancers (BTCs), including cholangiocarcinoma, ampulla of Vater and gallbladder cancer, are rare cancers with a poor prognosis $[1 \bullet]$. The incidence is increasing, mainly due to a rise in diagnosis of intrahepatic cholangiocarcinoma [2-4]. BTCs account for just 3\% of all gastrointestinal malignant tumours in adults [5]. Cholangiocarcinomas arise from epithelial cells of bile ducts and are subdivided according to the location of the primary tumour into intrahepatic, hilar and distal cholangiocarcinoma $[1 \bullet]$.

The peak incidence of BTC is between the ages of 50 and 70 years; cholangiocarcinoma is more frequent in males, while females have higher incidence of gallbladder cancer [5]. Medical conditions associated with chronic gallbladder or biliary tract inflammation (e.g. gallstones, gallbladder/biliary duct polyps, primary sclerosing cholangitis, chronic biliary/gallbladder infections, congenital anatomical abnormalities of the biliary tract) are known risk factors for developing BTCs [6-8].

The prognosis for patients with BTC is poor: the 5year survival (5-YS) is $5-15 \%$ when considering all patients $[9,10]$. The stage at presentation directly impacts on survival; the 5 -YS is $50 \%$ for stage I, $30 \%$ for stage II, $10 \%$ for stage III and $0 \%$ for stage IV $[11,12]$. Patients diagnosed with BTCs may present with biliary obstruction, due to local infiltration and occlusion of the biliary tract, mainly in patients with distal or hilar cholangiocarcinoma. In contrast, patients diagnosed with intrahepatic cholangiocarcinoma are more likely to present with non-specific right upper quadrant pain, which may delay diagnosis. Therefore, the majority of patients $(60-70 \%)$, and 
particularly those patients diagnosed with intrahepatic cholangiocarcinoma, will be diagnosed at an advanced stage of disease, when curative approaches are not available [13].

In addition, even in patients treated with curative resection for localised stages, the relapse rate is high $[11,14,15]$. Uncontrolled studies have explored adjuvant strategies in BTC patients following potentially curative surgery [16-18]; however, the results of prospective randomised studies are awaited (ACTICCA-1 [clinicaltrials.gov registration number NCT02170090], BILCAP [NCT00363584] and a study using gemcitabine/oxaliplatin in the adjuvant setting [NCT01313377] [19]).

\section{Treatment Options for Advanced Disease}

The most frequently used treatment modality is chemotherapy, particularly in the presence of systemic (usually extrahepatic) disease. The current reference regimen is cisplatin and gemcitabine based on the pivotal phase III study showing an advantage in overall survival (OS) from this combination compared to gemcitabine alone (11.7 vs. 8.1 months, respectively; $p<0.001$ ) [20•]. These findings were confirmed in a Japanese randomised phase II study (BT22 study) [21] (see Table 1). Other regimens using fluoropyrimidines (such as 5-fluorouracil), gemcitabine and other platinum agents, either in combination or as monotherapy [22-24], have been reported. However, their efficacy has not been confirmed in randomised phase III studies.

Following progression on first-line chemotherapy, approximately $15 \%$ of patients are suitable for further chemotherapy, mainly due to rapidly progressive disease and worsening performance status [25]. In addition, the magnitude of benefit, if any, from second-line chemotherapy is unknown [26•]. Active symptom control (e.g. by biliary stenting and antibiotics, as appropriate) is considered the standard of care in some countries as the benefit suggested by small prospective and retrospective studies [25, 27-29] has not been confirmed in prospective studies. The ABC-06 study (NCT01926236; [19]) is a randomised phase III trial which compares the combination of oxaliplatin and fluorouracil (FOLFOX) against active symptom control alone in patients with advanced BTC following progression on first-line cisplatin and gemcitabine; recruitment is ongoing.

Unlike patients with gallbladder cancer or distal cholangiocarcinoma, patients with intrahepatic cholangiocarcinoma may have liver-only (or liver-predominant) disease; in such cases, a liver-directed approach (e.g. RE) may be considered following systemic therapy $[30 \bullet, 31]$.

\section{Intrahepatic Cholangiocarcinoma: Morphology}

Cholangiocarcinoma presents with a variety of different morphological features secondary to variable cellular components, such as fibrous stroma, contributing to variable imaging appearances [32]. Intrahepatic cholangiocarcinoma is subclassified into three main types according to its features: mass forming, infiltrative and intraductal [33]. Identifying key imaging features of these subtypes aids in interpretation of imaging, prognostic factors and avenues for surgical and non-surgical management [34].

Mass-forming cholangiocarcinoma is characterised as a homogenous well-demarcated lesion with an irregular margin. The lesions commonly possess a capsular rim due to compression of the adjacent parenchyma which also results in biliary ductal dilatation and may precipitate patient presentation due to jaundice [35]. Due to the large fibrotic component of this subtype, capsular retraction and late centripetal enhancement are also common features [36]. Appearances on magnetic resonance imaging (MRI) are similar to those of computerised tomography $(\mathrm{CT})$ with delayed contrast enhancement and obliteration of the portal vein without visible tumour thrombus [37]. Uncommon features of this subtype include hypervascular enhancement suggestive of a welldifferentiated tumour [38]. Additionally, there are several mimics for mass-forming lesions including hepatocellular carcinoma (HCC) with cirrhotic stroma, sclerosing HCC and combined HCC and cholangiocarcinoma; therefore, these have to be considered particularly on a background of cirrhotic liver disease [39].

The periductal infiltrative subtype is uncommon; key features include a branchlike thickening of the intrahepatic ducts with or without ductal obliteration [40]. Imaging using CT and MRI shows periductal enhancement with ductal dilatation if found peripherally. However, this subtype is seen more commonly in the hilar region [41]. Differentials for the periductal subtype include lymphangitic metastasis and peribiliary cysts. Distinguishing features for cholangiocarcinoma include ductal dilatation and localised lobar disease [42].

The intraductal subtype has a variety of features such as ductal ectasia. The most common $\mathrm{CT}$ and MR imaging features are of diffuse ductal dilation with either a polypoid or plaque-like mass with post-contrast enhancement [43]. This form of cholangiocarcinoma is characterised by slow growth and a more favourable prognosis than its counterparts [44].

\section{Hepatic IAT}

The use of locoregional therapies in patients with intrahepatic cholangiocarcinoma is becoming more established [45]. Different methods of intra-arterial therapy include bland embolisation, trans-arterial chemoembolisation (TACE), the use of drug-eluting beads and radioembolisation. 
Liver intra-arterial therapy is a well-established locoregional therapy used in the treatment of patients with localised HCC, and its use in randomised trials has demonstrated a survival benefit [46]. The use of intra-arterial therapy (IAT) in cholangiocarcinoma is not as well documented; although studies have suggested a survival benefit, this evidence is limited to single-centre or retrospective studies [47] (see Table 2 for a summary of the most relevant studies). Additionally, the published studies use variable outcome measures to assess treatment benefit. Therefore, a true comparison of IAT with alternative treatments is limited.

HCC derives its blood supply from the hepatic arterial vessels, rather than the portal supply, providing an intrinsic advantage to the use of IAT [52]. In contrast, cholangiocarcinoma is not as hypervascular, and therefore, direct IAT may not provide as much benefit [53] and so is a potential limitation to its use in this setting.

Intra-arterial therapy is delivered directly into the hepatic arterial branches, and RE can be performed in a single step or as a two-stage procedure. The initial stage is to perform catheter angiography, establishing the arterial anatomy and identifying any aberrant vessels supplying the liver, as well as the gastric and gastro-duodenal arteries. Traditionally, the right gastric and gastroduodenal arteries are occluded and a test dose of technetium $\left({ }^{99 \mathrm{~m}} \mathrm{Tc}\right)$-microaggregated albumin (MAA) is delivered at the treatment point. Occlusion of the local right gastric and gastroduodenal arteries (GDA) is performed to prevent reflux of particles into these vessels and subsequent radiation enteritis. A ${ }^{99 \mathrm{~m}} \mathrm{Tc}$ MAA single-photon emission computed tomography (SPECT) CT is then performed to assess for extra-hepatic uptake and to calculate the lung shunt. Utilising the angiogram and the MAA SPECT CT data, a dose calculation can then be performed for the yttrium-90 $\left({ }^{90} \mathrm{Y}\right)$ microsphere treatment.

After the catheter angiography and MAA SPECT CT step, the procedure involves delivering the treatment particles (either in two separate doses into the right and left hepatic arteries depending on the distribution of disease or less commonly as a single dose to the entire liver when injected via the hepatic artery proper). Delivery of the particles in two separate doses, or in some cases three, allows more accurate dose calculation compared to one large-dose delivery.

The choice of particles for yttrium delivery is between two established glass and resin particles. Glass particles (TheraSpheres, MDS Nordion, Toronto, Ont, Canada) individually contain greater radioactivity; therefore, there is a reduced number of particles delivered per treatment compared to resin particles (SIR-Spheres; Sirtex Medical, Sidney, NSW, Australia), which individually contain a lower dose and so a larger number are delivered 
Table 2 Summary of the most relevant studies examining the use of RE therapy and its impact on overall survival

\begin{tabular}{|c|c|c|c|c|c|}
\hline Study design & Year & Reference & $\begin{array}{l}\text { Type of } \\
\text { intra- } \\
\text { arterial } \\
\text { therapy }\end{array}$ & $\begin{array}{l}\text { Patients } \\
\text { (n) }\end{array}$ & $\begin{array}{l}\text { Median overall } \\
\text { survival }\end{array}$ \\
\hline $\begin{array}{l}\text { Retrospective } \\
\text { multicentre } \\
\text { review }\end{array}$ & 2013 & $\begin{array}{l}\text { Hyder } \\
\text { et al. } \\
{[46]}\end{array}$ & $\begin{array}{l}\text { TACE } \\
\text { vs. } \\
\text { DEB } \\
\text { vs. } \\
\text { TAE } \\
\text { vs. } \\
\text { RE }\end{array}$ & 198 & $\begin{array}{l}\text { TACE } \\
13.4 \text { months } \\
\text { vs. DEB } \\
10.5 \text { months } \\
\text { vs. TAE } \\
14.3 \text { months } \\
\text { vs. RE } \\
11.3 \text { months }\end{array}$ \\
\hline $\begin{array}{r}\text { Systemic } \\
\text { review }\end{array}$ & 2014 & $\begin{array}{c}\text { Al-Adra } \\
\text { et al. } \\
{[30 \bullet]}\end{array}$ & $\mathrm{RE}$ & 298 & 15.5 months \\
\hline $\begin{array}{l}\text { Prospective } \\
\text { study }\end{array}$ & 2009 & $\begin{array}{c}\text { Saxena } \\
\text { et al. } \\
{[48]}\end{array}$ & $\mathrm{RE}$ & 25 & 9.3 months \\
\hline $\begin{array}{l}\text { Prospective } \\
\text { single } \\
\text { centre }\end{array}$ & 2012 & $\begin{array}{l}\text { Hoffmann } \\
\text { et al. } \\
\text { [49] }\end{array}$ & $\mathrm{RE}$ & 33 & 22 months \\
\hline $\begin{array}{l}\text { Prospective } \\
\text { single } \\
\text { centre }\end{array}$ & 2013 & $\begin{array}{c}\text { Rafi et al. } \\
\text { [50] }\end{array}$ & $\mathrm{RE}$ & 19 & 11.5 months \\
\hline $\begin{array}{l}\text { Prospective } \\
\text { single } \\
\text { centre }\end{array}$ & 2014 & $\begin{array}{c}\text { Mouli } \\
\text { et al. } \\
{[51]}\end{array}$ & $\mathrm{RE}$ & 46 & $\begin{array}{l}\text { Solitary lesion } \\
14.6 \text { months } \\
\text { vs. multifocal } \\
\text { lesions } \\
5.7 \text { months }\end{array}$ \\
\hline
\end{tabular}

TACE trans-arterial chemoembolisation, $D E B$ drug-eluting beads, TAE bland embolisation, $R E$ radioembolisation

per treatment [54]. A summary of the particle characteristics is provided in Table 3. Although a study has suggested a minimal survival advantage with the use of glass particles over resin [56], such evidence is limited with other publications reporting no difference [57].

\section{Considerations When Developing a Treatment Algorithm for the Treatment of Patients with Intrahepatic Cholangiocarcinoma}

Surgical resection, where possible, is the cornerstone of therapy; however, in patients presenting with advanced disease, this is not appropriate [58]. Systemic chemotherapy has an established, albeit modest, survival benefit [20•]. However, there is limited evidence supporting the use of RE in this patient subgroup. According to the National Comprehensive Cancer Network (NCCN) guidelines, chemotherapy is a recommended treatment option for patients with unresectable intrahepatic cholangiocarcinoma; there is a reference to the use of locoregional therapy but no specific reference to the use of RE (https://www.nccn.org/professionals/physician gls/ pdf/hepatobiliary.pdf). Additionally, comparative studies between systemic chemotherapy and RE are limited to single-centre, non-randomised studies or in the retrospective setting $[30 \bullet, 46,59]$. The use of RE in other hepatic malignancies such as colorectal liver metastases has been evaluated with a phase III clinical trial, randomising patients to firstline chemotherapy alone vs. chemotherapy and RE [60]. The results showed no improvement in overall PFS at any site; however, there was a significant delay in progression within the liver [60]. A systematic review by Al-Adra et al. reported a mean OS in patients with unresectable cholangiocarcinoma treated with RE therapy of 15.5 months [30•]. The reported survival is favourable in comparison to the previously reported median OS of 11.7 months in patients with advanced BTC treated with cisplatin/gemcitabine chemotherapy [20•]; therefore, within the limits of the evidence available, RE may be a potential treatment option.

A limitation to a number of the studies comparing various treatments includes the selection of a heavily pre-treated population; therefore, the true benefit of the therapy in question cannot be accurately tested [59]. Also, various methods have been used to calculate treatment response or to predict outcomes with a number of studies assessing treatment response using either Response Evaluation Criteria in Solid Tumours (RECIST) or modified RECIST (mRECIST) [61]. Camacho et al. concluded that the use of mRECIST criteria accurately predicted OS whereas RECIST did not in patients with advanced BTC [62].

Pre-treatment prior to RE treatment (i.e. with systemic chemotherapy) may mask the true benefit of RE. A study performed by Haug et al. reported prolonged survival in patients treated with RE who were chemotherapy-naïve. This was also reported in a study performed by Ibrahim et al. [59]; however, these conclusions must be interpreted with caution as the studies include small patient cohorts and are therefore prone to selection bias.

The volume of disease and liver function are key factors to consider when assessing patients for suitability for RE. Radioembolisation delivers a focal radiation dose to the liver parenchyma; therefore, those patients with large volume disease or underlying liver dysfunction will be at risk of liver failure, called radioembolisation-induced liver disease (REILD).

A consistent factor in predicted treatment outcome with RE therapy is patient performance status with a number of studies consistently showing that patients with better performance status have a greater OS postRE treatment. A study performed by Hoffmann et al. reported an OS benefit in patients with an Eastern Cooperative Oncology Group (ECOG) performance status of 0 versus 2 (29.4 months vs. 5.1 months) [49].

When considering treatment options, tumour volume, liver function and performance status are important factors to consider in addition to previous treatment received. A 
Table 3 Summary of the characteristics of the two particles used in RE therapy

\begin{tabular}{lll}
\hline Parameter & Resin & Glass \\
\hline Trade name & SIR-Spheres & TheraSpheres \\
Diameter & $22 \pm 10 \mu \mathrm{m}$ & $32 \pm 10 \mu \mathrm{m}$ \\
Specific gravity & $1.6 \mathrm{~g} / \mathrm{dL}$ & $3.6 \mathrm{~g} / \mathrm{dL}$ \\
Activity per particle & $50 \mathrm{~Bq}$ & $2500 \mathrm{~Bq}$ \\
Average number of microspheres per administered & $40-80$ million & $1.2-8$ million \\
$\quad$ activity & Resin with bound & Glass with yttrium in \\
Material & yttrium & matrix \\
\hline
\end{tabular}

Source: [55] multidisciplinary (MDT) approach will allow assessment of the essential factors to predict survival benefit and assess appropriate treatment.

\section{Discussion and Conclusions}

Radioembolisation is a novel modality of therapy for patients with metastatic liver disease and unresectable primary liver cancer. It is licensed in the UK for the treatment of patients with metastatic colorectal cancer without significant extrahepatic disease and in patients with cholangiocarcinoma where chemotherapy has failed (http://sirt.org.uk/sirt-uk.php).

The OS benefit appears to be favourable when compared to the reported literature on the use of non-IAT. The experience of its use at The Christie, within the limitations of the cohort size, supports a favourable OS advantage when compared to published survival figures for patients treated with alternative therapy acknowledging the retrospective setting.

Alternative intra-arterial therapy has been used in the treatment of patients with advanced BTC, including TACE and bland embolisation; however, there are no directly comparable randomised studies, and it is, therefore, difficult to compare survival statistics between these different locoregional treatment options. Additionally, patients treated with RE commonly have had previous treatment, which makes it difficult to assess the true benefit of RE alone.

Although there are no randomised trials, the published data is promising. The reported OS for patients diagnosed with unresectable cholangiocarcinoma treated with cisplatin/ gemcitabine combination is 11.7 months [20•]. An important factor reiterated in a number of studies is the impact of patient performance status on OS, with improved OS for patients with better performance status [45]. This is therefore important when considering a patient for RE and should be an essential element to any treatment algorithm. The underlying disease will impact on patient survival. Patients with primary cholangiocarcinoma who are suitable for radioembolisation will have liver-only disease and therefore will be stage I to III.
However, those patients with metastatic colorectal cancer would be, by definition stage IV, and are therefore more likely to have a poorer outcome. Due to an element of stage shift, patients will have variable survival depending on the underlying disease.

The variability in the patient cohort size, patient performance status, disease burden and previous treatment may contribute to discrepancies in OS figures reported in a number of studies. Although results are promising, larger, multicentre randomised trials comparing RE with alternative IATs and systemic chemotherapy are required to demonstrate whether RE provides a true benefit.

A study investigating the use of the cisplatin/gemcitabine combination +/- RE as first-line treatment for patients with unresectable intrahepatic cholangiocarcinoma (SIRCCA) is currently listed on clinical trials.gov (NCT02807181) but is not yet recruiting [19]. An additional listed study recruiting in Hong Kong aims to study the benefits of sequential administration of RE followed by standard chemotherapy for the treatment of inoperable intrahepatic cholangiocarcinoma (NCT02167711) [19]. The benefit of RE versus TACE for the treatment of patients with cholangiocarcinoma (NCT01798147) is also being evaluated. These studies should provide more guidance on the use and sequencing of this therapeutic modality in the treatment of patients with advanced BTC.

\section{Compliance with Ethical Standards}

Conflict of Interest Pavan Najran declares that he has no conflict of interest.

Angela Lamarca declares that she has no conflict of interest.

Damian Mullan declares that he has no conflict of interest.

Mairéad G. McNamara declares that she has no conflict of interest.

Thomas Westwood has received compensation from BTG for service as a consultant.

Richard A. Hubner declares that he has no conflict of interest.

Jeremy Lawrence has received compensation from Sirtex Medical for service as a consultant.

Prakash Manoharan has received compensation from Sirtex Medical and TheraSpheres for service as a consultant.

Jon Bell declares that he has no conflict of interest. 
Juan W. Valle has received compensation from Sirtex Medical for service as a consultant.

Human and Animal Rights and Informed Consent This article does not contain any studies with human or animal subjects performed by any of the authors.

Funding Angela Lamarca was funded by the Spanish Society of Medical Oncology (SEOM) Fellowship Grant.

Open Access This article is distributed under the terms of the Creative Commons Attribution 4.0 International License (http:// creativecommons.org/licenses/by/4.0/), which permits unrestricted use, distribution, and reproduction in any medium, provided you give appropriate credit to the original author(s) and the source, provide a link to the Creative Commons license, and indicate if changes were made.

\section{References}

Papers of particular interest, published recently, have been highlighted as:

- Of importance

1. Valle JW, Borbath I, Khan SA, Huguet F, Gruenberger T, Arnold D. Biliary cancer: ESMO Clinical Practice Guidelines for diagnosis, treatment and follow-up. Ann Oncol. 2016;27(suppl 5):v28-37. Summary of current guidelines for management of biliary tract malignancies

2. Patel T. Increasing incidence and mortality of primary intrahepatic cholangiocarcinoma in the United States. Hepatology. 2001;33: 1353-7.

3. Bertuccio P, Bosetti C, Levi F, et al. A comparison of trends in mortality from primary liver cancer and intrahepatic cholangiocarcinoma in Europe. Ann Oncol. 2013;24:1667-74.

4. Siegel RL, Miller KD, Jemal A. Cancer statistics, 2016. CA Cancer J Clin. 2016;66:7-30.

5. Edge S, Byrd DR, Compton CC, Fritz AG, Greene FL, Trotti A, editors. AJCC cancer staging manual. Springer-Verlag: New York; 2010.

6. Tyson GL, El-Serag HB. Risk factors for cholangiocarcinoma. Hepatology. 2011;54:173-84.

7. Zatonski WA, Lowenfels AB, Boyle P, et al. Epidemiologic aspects of gallbladder cancer: a case-control study of the SEARCH Program of the International Agency for Research on Cancer. J Natl Cancer Inst. 1997;89:1132-8.

8. Chapman RW. Risk factors for biliary tract carcinogenesis. Ann Oncol. 1999;10(Suppl 4):308-11.

9. Anderson C, Kim R. Adjuvant therapy for resected extrahepatic cholangiocarcinoma: a review of the literature and future directions. Cancer Treat Rev. 2009;35:322-7.

10. DeOliveira ML, Cunningham SC, Cameron JL, et al. Cholangiocarcinoma: thirty-one-year experience with 564 patients at a single institution. Ann Surg. 2007;245:755-62.

11. Wang Y, Li J, Xia Y, et al. Prognostic nomogram for intrahepatic cholangiocarcinoma after partial hepatectomy. J Clin Oncol. 2013;20(31):1188-95.

12. Bridgewater J, Lopes A, Wasan $\mathrm{H}$, et al. Prognostic factors for progression-free and overall survival in advanced biliary tract cancer. Ann Oncol. 2016;27:134-40.

13. Saha SK, Zhu AX, Fuchs CS, Brooks GA. Forty-year trends in cholangiocarcinoma incidence in the United States: intrahepatic disease on the rise. Oncologist. 2016;21:594-599
14. Endo I, Gonen M, Yopp AC, et al. Intrahepatic cholangiocarcinoma: rising frequency, improved survival, and determinants of outcome after resection. Ann Surg. 2008;248:84-96.

15. Wang SJ, Lemieux A, Kalpathy-Cramer J, et al. Nomogram for predicting the benefit of adjuvant chemoradiotherapy for resected gallbladder cancer. J Clin Oncol. 2011;29:4627-32.

16. Zhu AX, Knox JJ. Adjuvant therapy for intrahepatic cholangiocarcinoma: the debate continues. Oncologist. 2012;17:1504-7.

17. Horgan AM, Amir E, Walter T, et al. Adjuvant therapy in the treatment of biliary tract cancer: a systematic review and meta-analysis. J Clin Oncol. 2012;30:1934-40.

18. McNamara MG, Walter T, Horgan AM, et al. Outcome of adjuvant therapy in biliary tract cancers. Am J Clin Oncol. 2015;38:382-7.

19. U.S.National Institutes of Health: ClinicalTrials.gov.

20. Valle J, Wasan H, Palmer DH, et al. Cisplatin plus gemcitabine versus gemcitabine for biliary tract cancer. N Engl J Med. 2010;362:1273-81. Phase III clinical trial showing the benefit of first-line chemotherapy with cisplatin and gemcitabine for patients diagnosed with advanced biliary tract malignancies

21. Okusaka T, Nakachi K, Fukutomi A, et al. Gemcitabine alone or in combination with cisplatin in patients with biliary tract cancer: a comparative multicentre study in Japan. Br J Cancer. 2010;103:469-74.

22. Andre T, Tournigand C, Rosmorduc O, et al. Gemcitabine combined with oxaliplatin (GEMOX) in advanced biliary tract adenocarcinoma: a GERCOR study. Ann Oncol. 2004;15:1339-43.

23. Eckel F, Schmid RM. Chemotherapy in advanced biliary tract carcinoma: a pooled analysis of clinical trials. Br J Cancer. 2007;96: 896-902.

24. Tsavaris N, Kosmas C, Gouveris P, et al. Weekly gemcitabine for the treatment of biliary tract and gallbladder cancer. Investig New Drugs. 2004;22:193-8.

25. Bridgewater J, Palmer D, Cunningham D, et al.: Outcome of second-line chemotherapy for biliary tract cancer. Eur J Cancer, 2012.

26. Lamarca A, Hubner RA, Ryder WD, et al.: Second-line chemotherapy in advanced biliary cancer: a systematic review. Ann Oncol, 2014. Systematic review showing that role for second-line chemotherapy following progression to ciplatin-gemcitabine for patients diagnosed with advanced biliary tract cancer remains unanswered; this hihghlights one of the potential nitches for development of radioembolisation in intrahepatic cholangiocarcinoma.

27. Oh SY, Jeong CY, Hong SC, et al. Phase II study of second line gemcitabine single chemotherapy for biliary tract cancer patients with 5-fluorouracil refractoriness. Investig New Drugs. 2011;29: 1066-72.

28. Lee S, Oh SY, Kim BG, et al. Second-line treatment with a combination of continuous 5-fluorouracil, doxorubicin, and mitomycin-C (conti-FAM) in gemcitabine-pretreated pancreatic and biliary tract cancer. Am J Clin Oncol. 2009;32:348-52.

29. Sasaki T, Isayama $H$, Nakai $Y$, et al. Multicenter phase II study of S-1 monotherapy as second-line chemotherapy for advanced biliary tract cancer refractory to gemcitabine. Investig New Drugs. 2012;30:708-13.

30. Al-Adra DP, Gill RS, Axford SJ, et al. Treatment of unresectable intrahepatic cholangiocarcinoma with yttrium-90 radioembolization: a systematic review and pooled analysis. Eur J Surg Oncol. 2015;41:120-7. Systematic review exploring role of radioembolisation in patients diagnosed with intrahpetic cholangiocarcinoma

31. Edeline J, Du FL, Rayar M, et al. Glass microspheres $90 \mathrm{Y}$ selective internal radiation therapy and chemotherapy as first-line treatment of intrahepatic cholangiocarcinoma. Clin Nucl Med. 2015;40:851-5. 
32. Khan SA, Thomas HC, Davidson BR, Taylor-Robinson SD. Cholangiocarcinoma. The Lancet. 366(9493):1303-14.

33. Yang J, Yan L-N. Current status of intrahepatic cholangiocarcinoma. World J Gastroenterol WJG. 2008;14(41):6289-97.

34. Sasaki A, Aramaki M, Kawano K, Morii Y, Nakashima K, Yoshida $\mathrm{T}$, et al. Intrahepatic peripheral cholangiocarcinoma: mode of spread and choice of surgical treatment. Br J Surg. 1998;85(9): 1206-9.

35. Wernecke K, Henke L, Vassallo P, von Bassewitz DB, Diederich S, Peters PE, et al. Pathologic explanation for hypoechoic halo seen on sonograms of malignant liver tumors: an in vitro correlative study. AJR Am J Roentgenol. 1992;159(5):1011-6.

36. Lim JH. Cholangiocarcinoma: morphologic classification according to growth pattern and imaging findings. AJR Am J Roentgenol. 2003;181(3):819-27.

37. Maetani Y, Itoh $\mathrm{K}$, Watanabe $\mathrm{C}$, Shibata T, Ametani F, Yamabe H, et al. MR imaging of intrahepatic cholangiocarcinoma with pathologic correlation. AJR Am J Roentgenol. 2001;176(6):1499-507.

38. Yoshida Y, Imai Y, Murakami T, Nishikawa M, Kurokawa M, Yonezawa $\mathrm{T}$, et al. Intrahepatic cholangiocarcinoma with marked hypervascularity. Abdom Imaging. 1999;24(1):66-8.

39. Nishie A, Yoshimitsu K, Asayama Y, Irie H, Aibe H, Tajima T, et al. Detection of combined hepatocellular and cholangiocarcinomas on enhanced CT: comparison with histologic findings. AJR Am J Roentgenol. 2005;184(4):1157-62.

40. Mittelstaedt CA. Ultrasound of the bile ducts. Semin Roentgenol. 1997;32(3):161-71.

41. Lim JH, Park CK. Pathology of cholangiocarcinoma. Abdom Imaging. 2004;29(5):540-7.

42. Park M-S, Kim TK, Kim KW, Park SW, Lee JK, Kim J-S, et al. Differentiation of extrahepatic bile duct cholangiocarcinoma from benign stricture: findings at MRCP versus ERCP. Radiology. 2004;233(1):234-40.

43. Kawakatsu M, Vilgrain V, Zins M, Vullierme M, Belghiti J, Menu Y. Radiologic features of papillary adenoma and papillomatosis of the biliary tract. Abdom Imaging. 1997;22(1):87-90.

44. Chung YE, Kim M-J, Park YN, Choi J-Y, Pyo JY, Kim YC, et al. Varying appearances of cholangiocarcinoma: radiologic-pathologic correlation. Radiographics. 2009;29(3):683-700.

45. Hyder O, Marsh JW, Salem R, Petre EN, Kalva S, Liapi E, et al. Intra-arterial therapy for advanced intrahepatic cholangiocarcinoma: a multi-institutional analysis. Ann Surg Oncol. 2013;20(12): 3779-86.

46. Llovet JM, Real MI, Montana X, Planas R, Coll S, Aponte J, et al. Arterial embolisation or chemoembolisation versus symptomatic treatment in patients with unresectable hepatocellular carcinoma: a randomised controlled trial. Lancet Lond Engl. 2002;359(9319): 1734-9.

47. Burger I, Hong K, Schulick R, Georgiades C, Thuluvath P, Choti $\mathrm{M}$, et al. Transcatheter arterial chemoembolization in unresectable cholangiocarcinoma: initial experience in a single institution. J Vasc Interv Radiol JVIR. 2005;16(3):353-61.

48. Saxena A, Bester L, Chua TC, Chu FC, Morris DL. Yttrium-90 radiotherapy for unresectable intrahepatic cholangiocarcinoma: a preliminary assessment of this novel treatment option. Ann Surg Oncol. 2010;17(2):484-91.
49. Hoffmann R-T, Paprottka PM, Schon A, Bamberg F, Haug A, Durr E-M, et al. Transarterial hepatic yttrium-90 radioembolization in patients with unresectable intrahepatic cholangiocarcinoma: factors associated with prolonged survival. Cardiovasc Intervent Radiol. 2012;35(1):105-16

50. Rafi S, Piduru SM, El-Rayes B, Kauh JS, Kooby DA, Sarmiento JM, et al. Yttrium-90 radioembolization for unresectable standard-chemorefractory intrahepatic cholangiocarcinoma: survival, efficacy, and safety study. Cardiovasc Intervent Radiol. 2013;36(2):440-8.

51. Mouli S, Memon K, Baker T, Benson AB 3rd, Mulcahy MF, Gupta $\mathrm{R}$, et al. Yttrium-90 radioembolization for intrahepatic cholangiocarcinoma: safety, response, and survival analysis. J Vasc Interv Radiol JVIR. 2013;24(8):1227-34.

52. Lewandowski RJ, Salem R. Yttrium-90 radioembolization of hepatocellular carcinoma and metastatic disease to the liver. Semin Interv Radiol. 2006;23(1):64-72.

53. Walter JF, Bookstein JJ, Bouffard EV. Newer angiographic observations in cholangiocarcinoma. Radiology. 1976;118(1):19-23.

54. Sangro B, Inarrairaegui M, Bilbao JI. Radioembolization for hepatocellular carcinoma. J Hepatol. 2012;56(2):464-73.

55. Murthy R, Kamat P, Nuñez R, Salem R. Radioembolization of yttrium-90 microspheres for hepatic malignancy. Semin Interv Radiol. 2008;25(1):48-57.

56. Lam MG, Seinstra BA, van den Bosch M, Louie JD, Sze DY. Comparison between resin and glass microspheres for yttrium-90 radioembolization treatment of hepatocellular carcinoma. J Vasc Interv Radiol. 24(4):S149.

57. Soydal C, Kucuk ON, Bilgic S, Ibis E. Radioembolization with (90)Y resin microspheres for intrahepatic cholangiocellular carcinoma: prognostic factors. Ann Nucl Med. 2016;30(1):29-34.

58. Kuei A, Saab S, Cho S-K, Kee ST, Lee EW. Effects of yttrium-90 selective internal radiation therapy on non-conventional liver tumors. World J Gastroenterol WJG. 2015;21(27):8271-83.

59. Ibrahim SM, Mulcahy MF, Lewandowski RJ, Sato KT, Ryu RK, Masterson EJ, et al. Treatment of unresectable cholangiocarcinoma using yttrium-90 microspheres: results from a pilot study. Cancer. 2008;113(8):2119-28.

60. Van Hazel GA, Heinemann V, Sharma NK, Findlay MPN, Ricke J, Peeters M, et al. SIRFLOX: randomized phase III trial comparing first-line mFOLFOX6 (plus or minus bevacizumab) versus mFOLFOX6 (plus or minus bevacizumab) plus selective internal radiation therapy in patients with metastatic colorectal cancer. J Clin Oncol Off J Am Soc Clin Oncol. 2016;34(15):1723-31.

61. Eisenhauer EA, Therasse P, Bogaerts J, Schwartz LH, Sargent D, Ford R, et al. New response evaluation criteria in solid tumours: revised RECIST guideline (version 1.1). Eur J Cancer Oxf Engl 1990. 2009;45(2):228-47.

62. Camacho JC, Kokabi N, Xing M, Prajapati HJ, El-Rayes B, Kim HS. Modified response evaluation criteria in solid tumors and European Association for The Study of the Liver criteria using delayed-phase imaging at an early time point predict survival in patients with unresectable intrahepatic cholangiocarcinoma following yttrium-90 radioembolization. J Vasc Interv Radiol JVIR. 2014;25(2):256-65. 